\title{
Promising Drug Candidates for 2019-Novel Coronavirus (COVID-19) Pneumonia and Related Acute Respiratory Syndrome Treatment
}

\author{
Attapon Cheepsattayakorn ${ }^{1 *}$ and Ruangrong Cheepsattayakorn ${ }^{2}$ \\ ${ }^{1} 10$ th Zonal Tuberculosis and Chest Disease Center, Chiang Mai, Thailand \\ ${ }^{2}$ Department of Pathology, Faculty of Medicine, Chiang Mai University, Chiang Mai, \\ Thailand \\ *Corresponding Author: Attapon Cheepsattayakorn, 10th Zonal Tuberculosis \\ and Chest Disease Center, Chiang Mai, Thailand.
}

Received: February 18, 2020

Published: March 01, 2020

(C) All rights are reserved by Attapon

Cheepsattayakorn and Ruangrong

Cheepsattayakorn.
Patients with 2019-nCoV (COVID-19) infection are being recruited in randomized clinical trials to evaluate the efficacy of favipiravir plus phase III clinical trial were began in early February 2020 to evaluate intravenous remedesivir $(200 \mathrm{mg}$ on day 1 and $100 \mathrm{mg}$ once daily for 9 days) in 2019-nCoV (COVID-19)-infected patients (NCT04252664 and NCT04257656), with estimated completion dates in April 2020. Favipiravir (T-705), an approved guanine analogue with effective inhibition of the RNA-dependent RNA polymerase of RNA viruses was reported recently against 2019-nCoV (COVID-19) ( $\mathrm{EC}_{50}=61.88 \mu \mathrm{M}$ in Vero E6 cells). Other approved nucleoside analogues (ribavirin) and experimental nucleoside analogue (galidesivir) may have potential against 2019nCoV (COVID-19). Nucleoside analogues in the form of adenine or guanine derivatives target the RNA-dependent RNA polymerase and block viral RNA synthesis in a broad spectrum of RNA viruses, including human coronavirus.

HIV protease inhibitors (lopinavir and ritonavir) have been initiated to test in 2019-nCoV (COVID-19)-infected patients in clinical trials (ChiCTR2000029539, etc.). Lopinavir and ritonavir appeared to be associated with improved clinical outcomes of SARS and MERS patients in a non-randomized open-label trial by hypothesized inhibition of the 3-chymotrypsin-like protease of SARS and MERS. Nevertheless, it is questionable whether HIV protease inhibitors could effectively inhibit the papain-like and 3-chymotrypsin-like proteases of 2019-nCoV (COVID-19). Griffithsin, a red-alga-derived lectin (spike glycoprotein) is also a promising target against 2019-nCoV (COVID-19). Subcutaneous interferon therapies should be closely monitored and dose reduction or discontinuation of therapy may be needed due to its multiple adverse effects. Nitazoxanide could also inhibit 2019-nCoV (COVID-19) $\left(\mathrm{EC}_{50}=2.12 \mu \mathrm{M}\right.$ in Vero E6 cells). Chloroquine, an approved immune modulator demonstrates inhibitory effects against 2019$\mathrm{nCoV}$ (COVID-19) $\left(\mathrm{EC}_{50}=1.13 \mu \mathrm{M}\right.$ in Vero E6 cells). Small-molecule agents may also modulate the virus-host interactions of 2019nCoV (COVID-19).
In conclusion, further investigations for 2019-nCoV (COVID-19) therapeutic interventions are urgently needed due to its potentially global health threat, particularly antiviral efficacy of several promising agents in clinical trials.

\section{Assets from publication with us}

- Prompt Acknowledgement after receiving the article

- Thorough Double blinded peer review

- Rapid Publication

- Issue of Publication Certificate

- High visibility of your Published work

Website: https://www.actascientific.com/

Submit Article: https://www.actascientific.com/submission.php Email us: editor@actascientific.com

Contact us: +919182824667

Citation: Attapon Cheepsattayakorn and Ruangrong Cheepsattayakorn. "Promising Drug Candidates for 2019-Novel Coronavirus (COVID-19) Pneumonia and Related Acute Respiratory Syndrome Treatment". Acta Scientific Microbiology 3.4 (2020): 01. 